\section{Accuracy of Two Cephalometric Analyses in the Treatment of Patients with Skeletal Class III Malocclusion}

João Frank Carvalho Dantas' ${ }^{1}$ Sergio Henrique Gonçalves de Carvalho², Luciana Soares de Andrade Freitas Oliveira ${ }^{3}$, Danilo Batista Martins Barbosa $^{4}$, Raphael Freitas de Souza ${ }^{5}$, Viviane Almeida Sarmento ${ }^{6}$

The aim of the present study was to compare the treatment plan outlined from the diagnosis obtained by two different cephalometric analyses with the clinical decision made for surgical treatment of patients with skeletal Class III malocclusion. For this purpose, 82 skeletal Class III patients were evaluated, divided into three groups according to the surgical procedure performed for dentofacial deformity correction. Their preoperative cephalometric radiographs were submitted to McNamara and Steiner cephalometric analyses. The association of variables was evaluated by Kappa correlation $(\alpha=5 \%)$. The agreement between indication of surgical procedures performed based on clinical decision and surgical treatment indicated based on the evaluation of McNamara and Steiner cephalometric analyses were not significant $(p=0.609$ and $p=0.544$, respectively). McNamara and Steiner analyses showed reasonable agreement with each other as to the diagnosis, but did not agree with the clinical decision to treat skeletal CIII patients. Both tests were equally inaccurate in the indication of the surgical treatment.

\author{
'Dep. of Oral and Maxillofacial Surgery, \\ Portuguese Hospital, Salvador, BA, Brazil \\ ${ }^{2}$ Dep. of Propaedeutics, Dental School \\ of Araruna, UEPB - State University \\ of Paraíba, Araruna, PB, Brazil \\ ${ }^{3}$ Dep. of Applied Sciences, IFBA - Federal \\ Institute of Bahia, Salvador, BA, Brazil \\ ${ }^{4}$ Dep. of Oral and Maxillofacial \\ Surgery, Dental School of João \\ Pessoa, UFPB - Federal University \\ of Paraíba, João Pessoa, PB Brazil \\ ${ }^{5}$ Dep. of Dental Materials and \\ Prosthodontics, School of Dentistry \\ of Ribeirão Preto, USP - University of \\ São Paulo, Ribeirão Preto, SP, Brazil \\ ${ }^{6}$ Dep. of Propaedeutics and \\ Integrated Clinic, Dental School, \\ UFBA - Federal University of Bahia \\ - UFBA, Salvador, BA, Brazil
}

Correspondence: João Frank Carvalho Dantas, Avenida Anita Garibaldi, 1555 Sala: 806, 41.170-130 Salvador, BA, Brasil. Tel: +55-71-9979-1113. email: joaofrankdantas@yahoo.com.br

Key Words: orthognathic surgery, cephalometry, orthodontics, dentofacial deformities, diagnosis.

\section{Introduction}

Dentofacial deformities (DFD) affect about 20\% of the population. DFD patients show varying degrees of aesthetic and functional impairment, which may be restricted to a single jaw or extend to the entire craniofacial complex. There are several surgical-orthodontic techniques for correction of various deformities. The combination of surgery and orthodontic treatment proves to be a therapeutic modality where the patient can get a functional occlusion, combined with facial aesthetic within the standards (1). The combination of orthodontic treatment (OT) and orthognathic surgery is needed not only to obtain an aesthetics facial profile, but also to achieve a better masticatory and respiratory functions, motor development and phonation (2).

Before the advent of cephalometry, clinical analyses based on Angle's classification were used to categorize and diagnose malocclusion. The severity of malocclusion was usually interpreted as having skeletal implications. The use of cephalometric radiographs and different cephalometric analyses modified the diagnosis, especially in orthodontic and surgical cases. Cephalometry brought to the routine planning of orthodontists and surgeons measurement data useful for diagnosis and the possibility of analysis and radiographic determination of areas with altered, deficient or excess bone growth. A multitude of cephalometric parameters were created to study the different radiographic aspects of patient anatomy. Such analyses for identification and aid to treatment of orthodontic-surgical patients, either manual or digital, is a diagnostic method currently used and considered by many orthodontists and surgeons as standard for developing and determining the treatment plan, combined with facial analysis.

However, there is much controversy in the literature regarding the most appropriate cephalometric analysis for evaluation of patients who will undergo surgical orthodontic treatment (SOT). There is discussion whether these analysis methods diagnose correctly the exact location of the skeletal problem, and indicate the appropriate type of surgery to the patient and if these analyses are actually necessary. Parallel to diagnosis and definition of the treatment plan to achieve the ideal skeletal standards, it would be useless if the patient showed no satisfaction with the result achieved, since the SOT success depends not only on the perfect tooth alignment, correct bone repositioning by surgery, but also on the satisfaction of expectations and motivations that led the patient to seek treatment (3).

Therefore, the aim of this study was to compare the treatment plan outlined from the diagnosis obtained by means of McNamara and Steiner cephalometric analyses with the clinical decision made for surgical treatment of 
patients with skeletal Class III malocclusion.

\section{Material and Methods}

This research project was approved by the Ethics Committee of the Dental School of the Federal University of Bahia, under the protocol 216192 CAAE 0030.368.00008. Patients who agreed to participate in this study, read, agreed and signed the consent form designed for this purpose.

Skeletal CIII patients were considered eligible for this study, as long as they were aged between eighteen and fifty years, submitted to SOT performed by mandibular setback or maxillary advancement or both procedures, showing good quality pre-operative lateral cephalometric radiographs in their records. Osteotomies performed in all patients were limited to two bilateral sagittal split osteotomy (BSSO) and Le Fort I osteotomy using rigid internal fixation and no maxillomandibular fixation in the postoperative period. Patients were at least one year postoperative when participating in the study. Those who suffered accidents during the surgical procedures or postoperative infection were ineligible to participate. Total or partial edentulous patients in the anterior region, or those who had no occlusal contacts in the posterior region and patients who underwent surgery for chin advancement or setback concomitantly with Le Fort I osteotomy and BSSO were excluded. The chosen patients were from the Center for Research and Treatment of Oralfacial Deformities (CEDEFACE) from Araraquara, SP, Brazil.

Eighty-two skeletal CIII patients operated in a 9-year time span comprised the final sample. Patients were divided into three groups according to the surgical procedure, based on clinical assessment: Group A (GA) - Patients that had surgery for maxillary advancement combined with mandibular setback, Group B (GB) - patients submitted to maxillary advancement and Group C (GC) - patients who underwent a mandibular setback. Thirty patients were considered in $\mathrm{GA}, 36$ patients comprised $\mathrm{GB}$ and 16 patients comprised GC.

Preoperative cephalometric radiographs of each patient used in planning the surgical procedure were retrieved from medical records and scanned with transparency reader Snapscan 12365 SCSI model (AGFA) and $75 \mathrm{dpi}$ spatial resolution. Images were saved and filed in bmp format and identified with the number corresponding to the patient in the study.

McNamara and Steiner analyses were performed by a single trained examiner with expertise in computerized cephalometry using cephalometric analysis software (Radiocef ${ }^{\circledR}$; RadioMemory Corp., Belo Horizonte, MG, Brazil). The data obtained from McNamara and Steiner analyses were transferred to a database in Microsoft Office Exce ${ }^{\circledR} 2007$.

Values indicating the position of the maxilla and mandible from the base of the skull from both analyses were used. McNamara analysis is based on the assessment of the A-N.perp and Pog-N.perp values (Table 1). Steiner analysis is based on the assessment of the SNA and SNB values (Table 1). Values used as reference were obtained based on McNamara and Ellis III (4), McNamara (5) and Steiner (6).

After these assessments, each patient was categorized according to the possible options of cephalometric diagnostic patterns (4) and the possible diagnosis. Treatments for DFD correction by a proper positioning of the maxilla and/or mandible in relation to the skull base were indicated according to the normality patterns of bone positioning in both analyses (Table 2).

Participants answered a questionnaire about satisfaction with the treatment results to evaluate the possibility of satisfaction or dissatisfaction with the performed treatment based on clinical assessment. This questionnaire was previously used in other studies for the same purpose (7).

Association among variables was tested by Kappa correlation test $(\alpha=5 \%)$.

Table 1. Variation of McNamara and Steiner parameters for classification of horizontal positioning of the maxilla and mandible

\begin{tabular}{|c|c|c|c|}
\hline $\begin{array}{l}\text { Cephalometric } \\
\text { analysis }\end{array}$ & Retrusion & Normal & Protrusion \\
\hline \multicolumn{4}{|l|}{ McNamara } \\
\hline Maxilla & A-Nperp<-0.5 mm & $-0.5<A-N p e r p<2.5$ & A-Nperp $>2.5$ \\
\hline Mandible & $\begin{array}{c}\text { Pog-Nperp }<-2 \text { male patients } \\
\text { Pog-Nperp }<-4 \text { female patients }\end{array}$ & $\begin{array}{l}+2>\text { Pog-Nperp }>-2 \text { male patients } \\
-4>\text { Pog-Nperp }>0 \text { female patients }\end{array}$ & $\begin{array}{l}\text { Pog-Nperp }>+2 \text { male patients } \\
\text { Pog-Nperp }>0 \text { female patients }\end{array}$ \\
\hline \multicolumn{4}{|l|}{ Steiner } \\
\hline Maxilla & $\mathrm{SNA}<80.5 \mathrm{~mm}$ & $80.5>$ SNA $>83.5$ & $\mathrm{SNA}>83.5$ \\
\hline Mandible & $\mathrm{SNB}<78.5$ & $78.5>S N B>81.5$ & $\mathrm{SNB}>81.5$ \\
\hline
\end{tabular}




\section{Results}

The total sample consisted of 82 patients - 44 (53.7\%) females and $38(46.3 \%)$ males - with mean age of 26 years (18-48-year-old age rage). Distribution in the groups was as follows: 30 (36.6\%) patients belonged to GA, 36 (43.9\%) to $\mathrm{GB}$ and $16(19.5 \%)$ to $\mathrm{GC}$.

From the McNamara analysis for determining the appropriate treatment, patients belonged to 7 out of 9 possible groups: $23.2 \%$ belonged to Group 1, 2.4\% to Group 2, 3.7\% to Group 3, 2\% to Group 4, 3.7\% to Group 5, 1.2\% belonged to Group 6 and $43.9 \%$ to Group 7. No patient belonged to Groups 8 or 9 by the McNamara analysis.

From the Steiner analysis to determine the appropriate treatment, patients belonged to 7 out of 9 possible groups as follows: $19.5 \%$ belonged to Group 1, 13.4\% in Group $2,8.5 \%$ in Group 3; $19.5 \%$ in Group 4, 2.4\% in Group 5, 2.4\% belonged to Group 6 and 34.2\% in Group 7. No patient in the sample was classified in Groups 8 or 9 by the Steiner analysis.

Among the patients classified as GA, 16.7\% were classified by the McNamara analysis as Group $1 ; 6.7 \%$ as Group 3, and 26.7\% as Group 4, 3.3\% classified as Group 5, 3.3\% as Group 6 and 43.3\% were classified as Group 7; no patient in the GA was classified as Group 2.

Among the patients who made up $\mathrm{GB}, 30.6 \%$ were classified by the McNamara analysis as Group 1, 2.8\% as Group 2 and the same value as Group 3; $16.7 \%$ as Group $4,5.6 \%$ as a Group 5 and $41.7 \%$ as Group 7. No patient in

Table 2. Possible cephalometric diagnostic patterns, treatment plans indicated according to cephalometric normality patterns for bone positioning

\begin{tabular}{|c|c|c|}
\hline $\begin{array}{l}\text { Cephalometric } \\
\text { pattern }\end{array}$ & $\begin{array}{l}\text { Cephalometric } \\
\text { diagnosis }\end{array}$ & $\begin{array}{l}\text { Proposed } \\
\text { treatment }\end{array}$ \\
\hline 1 & $\begin{array}{l}\text { Retruded maxilla + } \\
\text { Protruded mandible }\end{array}$ & $\begin{array}{l}\text { Maxillary advancement + } \\
\text { and Mandibular setback }\end{array}$ \\
\hline 2 & $\begin{array}{l}\text { Retruded maxilla + } \\
\text { Neutral mandible }\end{array}$ & Maxillary advancement \\
\hline 3 & $\begin{array}{l}\text { Retruded maxilla + } \\
\text { Retruded mandible }\end{array}$ & $\begin{array}{l}\text { Maxillary advancement + } \\
\text { Mandibular advancement }\end{array}$ \\
\hline 4 & $\begin{array}{l}\text { Neutral maxilla + } \\
\text { Protruded mandible }\end{array}$ & Mandibular setback \\
\hline 5 & $\begin{array}{l}\text { Neutral maxilla }+ \\
\text { Neutral mandible }\end{array}$ & $\begin{array}{l}\text { Not need surgical } \\
\text { treatment }\end{array}$ \\
\hline 6 & $\begin{array}{l}\text { Neutral maxilla }+ \\
\text { Retruded mandible }\end{array}$ & Mandibular advancement \\
\hline 7 & $\begin{array}{l}\text { Protruded maxilla }+ \\
\text { Protruded mandible }\end{array}$ & $\begin{array}{l}\text { Maxillary setback + } \\
\text { Mandibular setback }\end{array}$ \\
\hline 8 & $\begin{array}{l}\text { Protruded maxilla + } \\
\text { Neutral mandible }\end{array}$ & Maxillary setback \\
\hline 9 & $\begin{array}{l}\text { Protruded maxilla + } \\
\text { Retruded mandible }\end{array}$ & $\begin{array}{c}\text { Maxillary setback + } \\
\text { Mandibular advancement }\end{array}$ \\
\hline
\end{tabular}

GB was classified as Group 6.

Of the total patients in $\mathrm{GC}, 18.8 \%$ were classified by McNamara analysis as Group 1; 6.3\% as Group 2, 3\% as Group 4 and $50 \%$ as Group 7. There were no patients in GC classified in Groups 3, 5 and 6.

Out of all patients classified as GA $26.7 \%$ were classified by the Steiner analysis as Group 1, 10\% as Group 2, 3.3\% as Group 3 and 23.3\% classified as Group 4, and the same value in Groups 5 and 6; 30\% as Group 7.

Among the patients belonging to $\mathrm{GB}, 22.2 \%$ were classified by Steiner analysis as Group 1, 8.3\% as Group 2, 13.9\% as Group 3, 22.2\% as Group 4, 2.8\% were classified as Group 5 and same percentage as Group 6 and 27.8\% classified as Group 7.

Out of the total patients in CG, 31.3\% were classified by Steiner analysis as Group 2, 6.3\% as Group 3; the same number of patients were classified as Group 4 and 56.3\% as Group 7. No patient in GC was classified in Groups 1, 5 and 6.

Agreement between the indication of performed surgical treatment and the proposed surgical treatment from the assessment of McNamara analysis was low by chance (Kappa=-0.019, 95\% confidence interval, from -0.091 to $0.053, p=0.6094)$, since only 10 patients $(12.2 \%$ of 82 patients) showed treatment performed and proposed by matching analysis (Table 3 ).

The agreement between the indication of performed surgical treatment and the proposed surgical treatment based on the evaluation of Steiner analysis was also low by chance (Kappa $=-0.0265,95 \%$ confidence interval: from -0.108 to $0.054, p=0.5442)$, since only 12 patients $(14.6 \%$ of 82 patients) showed treatment performed and proposed by coincident Steiner analysis, as shown in Table 4.

The degree of agreement between the indication for treatment and McNamara analysis and the indication of treatment by Steiner analysis was considered regular (Kappa $=0.305$ at 95\% confidence interval: from 0.173 to $0.437, p<0.0001)$. From the 82 patients evaluated 39 $(36 \%)$ had the same proposition of treatment from both analyses (Table 5).

The rate of satisfaction with the treatment performed

Table 3. Agreement between experimental groups and the groups classified by the McNamara analysis

\begin{tabular}{lcccccccc}
\hline Group & 1 & 2 & 3 & 4 & 5 & 6 & 7 & Total \\
\hline GA & 5 & 0 & 2 & 8 & 1 & 1 & 13 & 30 \\
GB & 11 & 1 & 1 & 6 & 2 & 0 & 15 & 36 \\
GC & 3 & 1 & 0 & 4 & 0 & 0 & 8 & 16 \\
Total & 19 & 2 & 3 & 18 & 3 & 1 & 36 & 82 \\
\hline
\end{tabular}


evaluated from the questionnaire was $97.6 \%$ (80 patients); only $2.4 \%$ (2) of patients were considered dissatisfied with the results of surgical treatment.

\section{Discussion}

For this survey were selected patients classified with a single pattern of malocclusion with the aim of limiting the analysis to one class of deformities only, providing more uniformity to the sample. The CIII was chosen by being often considered more disabling than the $\mathrm{Cll}$ and the orthognathic surgery is the solution to treatment success for a large number of individuals with CIII.

In the sample were found seven out of the nine possible groups from McNamara analysis. Ellis III and McNamara (4) in a study with similar division found distribution of the analyzed sample in all nine possible groups for the evaluation of CIII patients, but with a low number of patients in some groups (4).

In the present study were not included the standards ANS-Me, CO-A and CO-Gn of the McNamara analysis in the evaluation of maxillo-mandibular position, since their inclusion would lead to the formation of a high number of sub-groups derailing statistical analysis of data with a sample similar to the used one. The combination of A-N. perp and Pog-N.perp values in McNamara cephalometric analysis, and SNA and SNB values in the Steiner analysis have been previously used in scientific studies with similar methodology for determining the maxillomandibular positioning in relation to the skull base in order to evaluate the difference in the cephalometric pattern of CIII patients regarding the gender (8). The choice for analysis relating craniofacial structures with the Frankfort horizontal plane (FHP) and another that lists the structures with the sellanasion plane (SN) was due to a possible misinterpretation of the maxillomandibular position using a single reference plan, according to Ellis and McNamara (9). In addition, studies using SN should also include measures referenced to the FHP in order to be correlated.

The lower proportion of patients who made up the GC, patients who underwent mandibular setback, is due to mandibular setback being an avoided movement in

Table 4. Agreement between experimental groups and the groups classified by the Steiner analysis

\begin{tabular}{lcccccccc}
\hline Group & 1 & 2 & 3 & 4 & 5 & 6 & 7 & Total \\
\hline GA & 8 & 3 & 1 & 7 & 1 & 1 & 9 & 30 \\
GB & 8 & 3 & 5 & 8 & 1 & 1 & 10 & 36 \\
GC & 0 & 5 & 1 & 1 & 0 & 0 & 9 & 16 \\
Total & 16 & 11 & 7 & 16 & 2 & 2 & 28 & 82 \\
\hline
\end{tabular}

orthognathic surgery, because of the negative aesthetic changes promoted to the patient's profile (10), and the greater stability of surgical movements on maxillary advancement in relation to those on mandibular setback $(11,12)$. In addition, maxillary advancement or a combination of techniques determine lower long-term relapse, even in growing patients $(12,13)$.

Additionally, setback movements in maxilla and mandible are considered less predictable in terms of the soft tissue's final conformation. If there is option to setback or chin advance of another structure, the choice for advancement is preferable by having less postoperative recurrence and due to the fact that face bone tissue response to expansion is more predictable and aesthetically pleasing (10). In this study, 80.5\% of patients underwent maxillary advancement surgery or maxillary advancement combined with mandibular setback and only 19.5\% underwent mandibular setback surgery.

From the 9 possible groups, using the evaluation patterns of McNamara and Steiner analyses, 7 groups were formed from the sample studied for both analyses. No patient was framed in Groups 8 and 9, protruded maxilla with neutral mandible and protruded maxilla with retruded mandible, respectively. In a study with similar division into groups using the same cephalometric patterns of Ellis III and McNamara (4) were found $1.6 \%$ and $0.33 \%$ patients in the sample with cephalometric pattern compatible to Groups 8 and 9, respectively.

For both analyses, the group with largest number of patients was group 7, combination of protruded maxilla and protruded mandible, with $43.9 \%$ of the sample analyzed by the McNamara analysis and $34.2 \%$ by Steiner analysis. This sets the patient with cephalometric pattern compatible with skeletal biprotrusion CIII malocclusion. This cephalometric pattern can be explained by a shortening of

Table 5. Agreement among groups classified by McNamara (vertical) and Steiner (horizontal) analyses

\begin{tabular}{lcccccccc}
\hline Group & 1 & 2 & 3 & 4 & 5 & 6 & 7 & Total \\
\hline 1 & 10 & 2 & 2 & 2 & - & - & 3 & 19 \\
2 & - & 1 & - & - & - & - & 1 & 2 \\
3 & - & 1 & 1 & - & 1 & - & - & 3 \\
4 & 5 & 3 & 1 & 6 & - & - & 3 & 18 \\
5 & - & 1 & 1 & - & - & - & 1 & 3 \\
6 & - & - & - & - & - & 1 & - & 1 \\
7 & 1 & 3 & 2 & 8 & 1 & 1 & 20 & 36 \\
Total & 16 & 11 & 7 & 16 & 2 & 2 & 28 & 82 \\
\hline
\end{tabular}

Zero values were replaced by the sign "-" for better data visualization. 
the cranial base in these individuals. Thus, the combination of protruding bone of the maxilla and mandible is only relative; these structures can indeed be in normal position (4). McNamara (5) describes that the perpendicular nasion line is usually accurate in determining maxillary position, except for CIII patients with low length of the cranial anterior base, in those cases where the posterior position of the nasion results in the construction of an erroneous nasion-perpendicular line, giving the appearance of forward positioned maxilla and mandible. Altered nasion position can also change the SNA and SNB angles, since nasion retro-positioning may be a factor in the increased values of these two measures. The length of the anterior cranial base (SN) is smaller in Class III patients, allowing the appearance of increased SNA angles (14). The analyzed sample had possibly smaller skull base dimensions compared to samples of Ellis and McNamara (4) and McNamara (5), which would explain the higher proportion of patients classified with protruded mandible in conjunction with protruded maxilla.

Group 1 was the second most numerous in the McNamara evaluation with $23.2 \%$ followed by $22 \%$ in Group 4. In the Steiner evaluation, Group 1 and Group 4 a had equal percentages: $19.5 \%$. Group 2, formed by the McNamara evaluation, was the sixth most numerous with only $2.44 \%$ of the total sample. When evaluated by Steiner analysis, it was the fourth most numerous with $13.4 \%$ of the total sample. In both tests there is a tendency to consider the mandibular positioning of CIII patients as protruded, $89 \%$ and $73.2 \%$ of patients evaluated by McNamara and Steiner analyses, respectively. There is a tendency to consider the maxillary positioning as neutral or protruded, 29.3\% and $41.5 \%$ respectively, indicating that the main cause of CIII problems is the mandible protrusion, with or without maxillary retraction.

Out of the patients clinically grouped in $\mathrm{GA}, \mathrm{GB}, \mathrm{GC}$, most were classified by the McNamara analysis as Group 7 with $43.3 \%, 41.7 \%$ and $50 \%$ of the sample of each clinical group, respectively. The second largest group composing the GA sample was Group 4 with only $26.7 \%$ and $16.7 \%$ of the sample comprised the Group 1, which configures agreement between the treatment performed and treatment indicated by the McNamara analysis. For $\mathrm{GB}$, the second largest group was the Group 1 with 30.6\%, followed by Group 4 with $16.67 \%$, the Group 2 presenting agreement between clinical treatment and that indicated by the analysis, with only $2.78 \%$. In GC, the second largest group was Group 4, which showed agreement between the two treatments.

From the patients clinically grouped in $\mathrm{GA}, \mathrm{GB}, \mathrm{GC}$, most were classified by the Steiner analysis also as Group 7 (30\%, 27.8\% and 56.3\%, respectively), but with lower percentages for $\mathrm{GA}$ and $\mathrm{GB}$ and slightly higher for $\mathrm{GC}$. The second largest group composing the GA sample was Group 1 with 26.7\%. This group showed agreement between the performed treatments and those indicated by the cephalometric analysis, followed by Group 4 with $23.3 \%$. In GB Groups 1 and 4 were the most numerous after Group 7, both featuring the same percentage: $22.2 \%$. Group 2, which showed correlation between the treatments performed and indicated by the analysis, was only $8.3 \%$.

For GC, the second largest group was 2 with $31.3 \%$ and Groups 3 and 4 had the same percentage (6.3\% of the sample), the latter being in agreement between the treatments performed and indicated by the analysis.

For all clinical groups ( $\mathrm{GA}, \mathrm{GB}$ and $\mathrm{GC}$ ) in both cephalometric analyses, Group 7 was the most prevalent, since most patients who comprised the sample were cephalometrically classified as belonging to Group 7. This bias is due to the shortening of the skull base in CIII patients that determines higher values of the measures evaluated in the cephalometric analysis, providing a skeletal biprotrusion diagnosis, which clinically is not really observed (5).

For both surveys in $\mathrm{GB}$, there was low correlation between treatments. This can be explained by the tendency of both tests to consider that the main cause of CIII problems is mandible protrusion, associated or not with maxillary retrusion. Thus, they do not indicate maxillary advancement as a treatment for normalization of mandibular bone positioning.

From the above, it may be inferred that the use of cephalometric analyses in the preparation of the surgical planning of patients who will undergo orthognathic surgery should be performed with caution. The cephalometric analyses are performed using standards and patterns from data analysis obtained by lateral cephalograms of individuals in specific populations, considered with good aesthetics and good occlusion $(5,6)$. Thus, the diagnosis obtained by them may not correspond to normal occlusion or aesthetics of patients in other populations (15-18). Cephalometric values of previously described analyses should not be applied to different populations, even when the evaluated patients have good occlusion and good facial aesthetics $(16,18,19)$. Many authors have developed analyses adapting cephalometric values of previous analyses (14-18). In this study, it may be inferred that the cephalometric patterns of North-American population do not represent correctly the facial features of the evaluated sample.

The use of cephalometric values to determine the type of treatment is much reported in the literature, from the therapeutic decision (if the patient should be treated only in orthodontic terms or through SOT) (20) up to to define which surgical technique and bone movement must be performed from the categorization of each patient into groups based on combinations of cephalometric patterns 
$(18,20,21)$. The divergence between treatment plans based on cephalometric analyses and treatment plans made from the clinical diagnosis has been previously reported in the literature (22).

The differences among treatment plans designed only for trying to normalize cephalometric values in relation to treatment plans made from the clinical examination can be explained by several factors. Thus, the possibility to assess the soft tissues conformation, inter-arcs relationship, smile conformation and interaction between the integument at rest and during animation is restricted to cases in which clinical examination is taken into account for preparing the treatment plan and cannot be evaluated by radiographs $(1,22)$. DFD correction by SOT emphasizes that obtaining a $\mathrm{Cl}$ occlusion should be obtained with predictability and stability, but aesthetic concepts should dictate the course of such correction. The morphologic evaluation of bone and soft tissue of the face must be taken into account, since clinical findings may differ from the quantitative findings of cephalometry. Thus, the treatment plan cannot be based only on strict standards of cephalometric values and previously established anthropometric values (10). Strict adherence to a treatment plan based on the cephalometric values may provide unsatisfactory results if there is disagreement between cephalometric diagnosis and clinical diagnosis in determining the degree and location of DFD. Results of this study confirm this assertion.

Support of the soft tissues may be one of the most critical factors in determining the aesthetic orthognathic surgery. Therefore, blind use of anthropometric and cephalometric values in determining the treatment plan should be viewed with caution (22). The error of this assessment is that normality of these standards is not always synonymous with beauty or attractive aesthetics. Many individuals considered as symmetric and within the cephalometric and anthropometric standards are not considered attractive, and there are many individuals that are out of those standards that are considered very beautiful and attractive (10). Aesthetic impression and facial harmony are subjective factors (22).

Divergence in treatment plans determined by cephalometric evaluations and caution in the use of cephalometric analyses are often cited in literature $(10,22)$, but no study that statistically evaluated the presence or absence of agreement as analyzed here was found.

Programs that use two- or three-dimensional digital cephalometry as a diagnostic tool tend to lead to misdiagnosis or difference from the clinical diagnosis, as they instill the same problem using conventional twodimensional cephalometry: a profile based on standards obtained for a particular group or population that cannot be applied to other groups or different populations at risk of generating an inaccurate diagnosis and difference from the observed clinical reality. It should be emphasized that getting a realistic and accurate diagnosis should be the basis for preparing a treatment plan, but they are two distinct phases of treatment. The use of cephalometric radiographs, photographs or three-dimensional images in the development of treatment options, whether by manual tracing or modern programs of surgical planning are essential in choosing the treatment to be performed. However, just following the numerical results of the various cephalometric analyses without taking into account other aspects for treatment development can be a big mistake.

The result was considered as regular (kappa 0.305, $p<0.0001)$ when the degree of correlation between the diagnosis obtained was evaluated by the McNamara and Steiner analyses and between each other by the Kappa correlation test. From the 82 evaluated patients, 39 presented the same treatment proposition from both tests. Differences between results of Steiner and McNamara analyses were expected, since each one uses a different horizontal plane as reference, and measurements using different plans, even assessing the position of the same structures may result in different diagnosis (9). Although FHP is considered as more accurate in relation to the SN plan in cephalometric measurements (9), both plans may have different results than the one found clinically. Sometimes the measurements obtained based on the SN plan or measurements obtained from the FHP may be more accurate in relation to clinical findings in specific cases (23).

The rate of satisfaction with the treatment performed on the patients in the present study was $97.6 \%$ of the total sample and only $2.4 \%$ were dissatisfied by the used methodology. High satisfaction scores in studies assessing satisfaction with SOT are common $(7,18,20)$. The high rate of satisfaction of patients may be explained by the impact of DFD Class III correction in the patient's lives, since this deformity is reported as the most disabling and for a great number of individuals the actual result for their DFD treatment can only be achieved by orthognathic surgery.

Based on the used methodology and outcomes, it is not unreasonable to assume that the indication of surgical treatment from the diagnosis obtained with McNamara and Steiner analyses shows no correlation with the clinical decision to treat skeletal CIII patients, and both analyses have limited application in developing the treatment plan for CIII patients. McNamara and Steiner cephalometric analyses were also inaccurate in the indication of surgical treatment, compared with the clinical decision, determining incorrect diagnosis regarding the reality of DFD conformation in CIII patients. McNamara and Steiner cephalometric analyses showed reasonable agreement between each other for DFD diagnosis of CIII patients. 


\section{Resumo}

0 objetivo deste trabalho foi comparar o plano de tratamento delineado a partir do diagnóstico obtido através de duas análises cefalométricas distintas, com a decisão clínica tomada para o tratamento cirúrgico de pacientes portadores de maloclusão classe III esquelética. Para isto foram avaliados 82 pacientes classe III esquelética, divididos em três grupos de acordo com o procedimento cirúrgico realizado para a correção da deformidade dentofacial. Suas radiografias cefalométricas pré-operatórias foram submetidas à análise cefalométrica de McNamara e de Steiner. A associação das variáveis foi avaliada pelo teste de correlação de Kappa $(\alpha=5 \%)$. A concordância entre a indicação do tratamento cirúrgico baseado na decisão clínica e o tratamento cirúrgico proposto a partir da avaliação das análises de McNamara e de Steiner não foi significante ( $p=0,6094$ e $p=0,5442$,respectivamente). As análises de McNamara e de Steiner apresentaram concordância razoável entre si para o diagnóstico, porém não apresentam concordância com a decisão clínica para o tratamento de pacientes CIII esquelética, sendo as duas análises igualmente imprecisas na indicação do tratamento cirúrgico dos pacientes da amostra.

\section{Acknowledgements}

We thank Dr. Roberto Della Coletta, CEDEFACE's president, and Dr. Mario Gabrielli, professor of Oral and Maxillofacial Surgery at Araraquara Dental School, UNESP for the support given to this work

\section{References}

1. Vig KD, Ellis E III. Diagnosis and treatment planning for the surgicalorthodontic patient. Dent Clin North Am 1990;34:361-384.

2. Bellucci CC, Kapp-Simon KA. Psychological considerations in orthognathic surgery. Clin Plast Surg 2007;34:11-16.

3. Oland J, Jensen J, Elklit A, Melsen B. Motives for surgical-orthodontic treatment and effect of treatment on psychosocial well-being and satisfaction: a prospective study of 118 patients. J Oral Maxillofac Surg 2011;69:104-1\%13.

4. Ellis E III, McNamara JA Jr. Components of adult Class III malocclusion. J Oral Maxillofac Surg 1984;42:295-305.

5. McNamara JA Jr. A method of cephalometric evaluation. Am J Orthod 1984;86:449-469.

6. Steiner CC. Cephalometrics for you and me. Am J Orthod 1953;39:729775.

7. Dantas JFC, Neto JNN, Carvalho SHG, Martins IMCLB, de Souza RF, Sarmento VA. Satisfaction of skeletal Class III patients treated with different types of orthognathic surgery. Int J Oral Maxillofac Surg 2014;30:264-271.

8. Lew KK, Foong WC. Horizontal skeletal typing in an ethnic Chinese population with true Class III malocclusions. Br J Orthod 1993;20:1923.

9. Ellis E III, McNamara J Jr. Cephalometric reference planes--sella nasion vs Frankfort horizontal. Int J Adult Orthodon Orthognath Surg 1988;3:81-87.

10. Selber JC, Rosen HM. Aesthetics of facial skeletal surgery. Clin Plast Surg 2007;34:437-445.

11. Proffit WR, Turvey TA, Phillips C. The hierarchy of stability and predictability in orthognathic surgery with rigid fixation: an update and extension. Head \&t Face Medicine 2007;3:21.

12. Proffit WR, Phillips C, Turvey TA. Stability after mandibular setback: mandible-only vs two-jaw-surgery. J Oral Maxillofac Surg. 2012;70:e408-e414.

13. Bailey $\amalg$, Phillips C, Proffit WR. Long-term outcome of surgical Class III correction as a function of age at surgery. Am J Orthod Dentofacial Orthop. 2008;133:365-370.

14. Singh GD. Morphologic determinants in the etiology of Class III malocclusions: a review. Clin Anat 1999;12:382-405.

16. Shindoi JM, Matsumoto $Y$, Sato $Y$, Ono T, Harada K. Soft tissue cephalometric norms for orthognathic and cosmetic surgery. J Oral Maxillofac Surg 2013;71:e24-e30. doi: 10.1016/j.joms.2012.08.015. Epub 2012 Oct 23.

17. Upadhyay JS, Maheshwari S, Verma SK, Zahid SN. Soft tissue cephalometric analysis applied to regional Indian population. Natl J Maxillofac Surg 2013;4:159-166.

18. Yadav AO, Walia CS, Borle RM, Chaoji KH, Rajan R, Datarkar AN. Cephalometric norms for Central Indian population using Burstone and Legan analysis. Indian J Dent Res. 2011;22:28-33.

19. Hong SX, Yi CK. A classification and characterization of skeletal class III malocclusion on etio-pathogenic basis. Int J Oral Maxillofac Surg 2001;30:264-271.

20. Folaranmi N, Isiekwe M. Anterior face height values in a Nigerian population. Ann Med Health Sci Res 2013;3:583-587.

21. Dipaolo RJ, Philip C. The role of cephalometrics in surgical orthodontics. NY State Dent J 1982;48:102-104,106.

22. Alves e Silva AC, Carvalho RA, Santos TS, Rocha NS, Gomes AC, Oliveira e Silva ED. Evaluation of life quality of patients submitted to orthognathic surgery. Dental Press J Orthod 2013;18:107-114.

23. Wylie GA, Fish LC, Epker BN. Cephalometrics: a comparison of five analyses currently used in the diagnosis of dentofacial deformities. Int J Adult Orthodon Orthognath Surg 1987;2:15-36.

24. Incisivo $V$, Silvestri $A$. The reliability and variability of $S N$ and PFH reference planes in cephalometric diagnosis and therapeutic planning of dentomaxillofacial malformations. J Craniofac Surg 2000;11:31-38.

Received November 27, 2014 Accepted January 7, 2015 